\title{
THE EFFECT OF COPPER ON THE DISTRIBUTION OF ELEMENTS IN HUMAN SPERMATOZOA
}

\author{
P. V. MAYNARD, MAX ELSTEIN* AND J. A. CHANDLER \\ Tenovus Institute for Cancer Research, Welsh National School of Medicine, \\ Heath Park, Cardiff CF4 $4 X X$, and \\ *Department of Human Reproduction and Obstetrics, Faculty of Medicine, \\ University of Southampton, Southampton SO1 $6 H U$
}

(Received 17th Fuly 1974)

\begin{abstract}
Summary. Examination of intact individual human spermatozoa by $\mathrm{X}$-ray microanalysis revealed that there was a correlation between particular elements in different regions of the cell. There was a constancy in the ratios of sodium to potassium in the head and mid-piece and of calcium to phosphorus in the mid-piece in any one sample, though the ratios varied between samples. This may have reflected the external environment since immersion in culture medium or cervical mucus had little effect on motility, yet markedly altered the sodium:potassium ratio.

Incubation with copper wire in semen or cervical mucus significantly reduced the subcellular levels of both sodium and potassium in spermatozoa but did not affect the ratio between these two elements. The metal also displaced zinc from the head region, possibly replacing it by copper. This may account for the decreased motility of spermatozoa in contact with copper ions.

The observed toxicity of copper for human sperm cells lends support to the theory that part of the mode of action of the copper IUD may be due to an alteration in sperm fertilizing potential. Although the level of copper released by IUDs containing $200 \mathrm{~mm}^{2}$ of copper wire exerted a minor toxic effect on spermatozoa, the elemental changes observed here may have great significance in the development of more efficient copperreleasing IUDs or an intracervical device whose action would depend on its spermatotoxic effect.
\end{abstract}

\section{INTRODUCTION}

A number of hypotheses have been proposed for the biological action of copper used in the copper intrauterine device (Cu-IUD) first developed by Zipper, Tatum, Medel, Pastene \& Rivera (1971), and now in increasingly common use. The toxic action of copper ions on the preimplantation embryo has been reported by Brinster \& Cross (1972), and on the reduction in implantation sites by Chang, Tatum \& Kincl (1970). Oster (1972) found that spermatozoa incubated with cervical mucus that had been in contact with copper became inactivated, and it was shown by Saito, Bush \& Whitmore (1967) in the rat and dog that cadmium and copper are toxic to spermatozoa whereas zinc enhances the motility. 
Enzymes such as alkaline phosphatase and carbonic anhydrase, both containing zinc and essential for sperm motility, have been found to be inactivated by the presence of copper ions (Oster, 1972).

Zipper, Tatum, Pastene, Medel \& Rivera (1969) have postulated a number of possible effects of copper on fertility: (i) change in the endometrial milieu, (ii) alteration of the biochemistry of the endometrial and tubal mucosa, (iii) change in the physicochemical characteristics of the cervical mucus, and (iv) toxic effects on sperm cells. Rush \& Elstein (1974) have shown that the latter two are minor factors at the level of copper released from IUDs containing $200 \mathrm{~mm}^{2}$ copper wire. These factors may be of considerable significance, however, in the development of intracervical contraceptive devices whose primary mode of action would be to provide an environment hostile to the sperm cells.

This study is concerned with the toxic effect in vitro of copper on sperm cells and describes changes which occur in subcellular elemental distributions as a consequence of incubating human semen with copper and with cervical mucus.

\section{MATERIALS AND METHODS}

\section{Specimen preparation}

Semen samples were collected into sterile containers from donors at the Fertility Clinic, University Hospital of Wales, Cardiff. The samples were then allowed to liquefy at $37^{\circ} \mathrm{C}$ for at least $30 \mathrm{~min}$. Subsequent incubations were performed at $37^{\circ} \mathrm{C}$ in a shaking water-bath.

Copper wires (Baird \& Tatlock, Essex) with a surface area of $100 \mathrm{~mm}^{2}$ and a purity of $>99.9 \%$ as determined by X-ray analysis were used. These were incubated individually with $0.25 \mathrm{ml}$ semen for $2 \mathrm{hr}$, together with control samples containing no metal wire. Estimations of sperm motility were made after each incubation by assessing the numbers of motile and immotile spermatozoa in a known field under a light microscope.

The cervical mucus used in the experiments was obtained from donors attending the Southampton University Fertility and Research Contraceptive Clinics in the preovulatory phase of the menstrual cycle. Portions of mucus $(0.2 \mathrm{ml})$ were incubated for $2 \mathrm{hr}$ at $37^{\circ} \mathrm{C}$ either alone or with $40 \mathrm{~mm}^{2}$ copper wire. Further 2-hr incubations were performed with the control and treated mucus after the addition of $0.25 \mathrm{ml}$ semen. In these second incubations using the copper-treated mucus, the copper wire was retained in alternate specimens.

Spermatozoa were concentrated by centrifuging the specimens for $10 \mathrm{~min}$ at $750 \mathrm{~g}$ and then air-drying samples mounted on carbon electron microscope grids for analysis.

In some specimens, repeated washing of spermatozoa with culture medium was attempted. This induced marked changes in subcellular elemental levels, however, particularly for sodium and potassium, and the modification was not adopted.

\section{Instruments}

The electron microscope microanalyser, EMMA, used in this study allowed 
the elemental analysis of small regions of cells by the collection of X-rays from the specimen whilst observing it by transmission electron microscopy. Thus, ultrastructure and local analysis could be effectively studied simultaneously (Chandler, 1973, 1974). Detection of X-rays in the EMMA was by means of a $\mathrm{Si}(\mathrm{Li})$ energy dispersive detector linked to a 1000 channel analyser, providing a semiquantitative energy spectrum, and also by a double crystal spectrometer system which allowed a more sensitive and accurate quantification for particular elements. The 'mass thickness' of the specimen, necessary to obtain the relative concentrations of elements from one spermatozoon to the next, was assessed by determination of the 'white radiation' of the spectrum. The relative concentration of a given element presented here was given by the ratio of the characteristic X-ray signal and the white radiation (Hall, 1971). Text-figure 1 represents an X-ray energy spectrum obtained from the head of a single sperm cell and Plate 1 shows the areas of the cell that could be measured. In these experiments, only the head and mid-piece were studied.

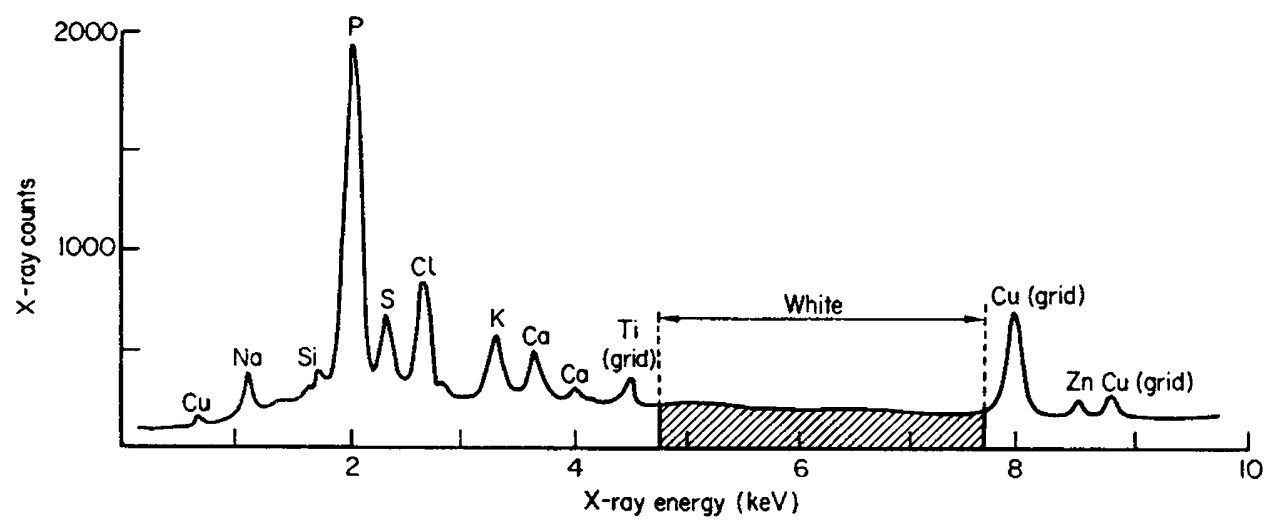

TEXT-FIG. 1. X-ray spectrum of elements analysed in the head of a single normal human sperm cell. The Ti, Si and $\mathrm{Cu}$ peaks are mostly due to stray X-rays from the microscope and are ignored. Other peaks are from endogenous elemental levels within the cell.

\section{RESULTS}

Analyses of normal cells

Table 1 shows the results of analyses of a number of semen samples with apparently normal characteristics, i.e. counts of over $50 \times 10^{6}$ spermatozoa $/ \mathrm{ml}$, motility greater than $70 \%$, and an acceptable number of abnormal cells $(<30 \%)$. In each sample of semen (one sample from six different subjects), both the head and mid-piece regions of fifteen individual sperm cells were analysed.

A wide variation in the concentrations of the different elements was found between individual sperm cells from the different samples of semen (Table 1).

Table 2 indicates a relatively small variation (30\% standard deviation) in each sample between sodium and potassium in both head and mid-piece and between calcium and phosphorus in the mid-piece despite the high \% deviation of calcium from cell to cell. 
Copper incubations

Text-figure 2 shows the results of analyses of spermatozoa treated with copper.

The copper wire significantly decreased the sodium content of the head and mid-piece $(P<0.001$, Student's $t$ test $)$ and also the potassium in the head $(P<0.001)$. During copper incubation, the zinc content of spermatozoa was also decreased in the head $(P<0.001)$ and mid-piece $(P<0.025)$, possibly being displaced by copper which increased in both the head $(P<0.025)$ and midpiece $(P<0.02)$.

Table 1. Analysis of the concentrations of various elemental constituents in the heads and mid-pieces of normal human spermatozoa

\begin{tabular}{|c|c|c|c|c|c|c|}
\hline \multirow[t]{2}{*}{ Element } & \multicolumn{2}{|c|}{$\begin{array}{l}\text { Average of means } \\
\text { from six subjects* }\end{array}$} & \multicolumn{2}{|c|}{$\begin{array}{c}\text { Variability } \\
\text { between subjects } \uparrow\end{array}$} & \multicolumn{2}{|c|}{$\begin{array}{c}\text { Variability } \\
\text { between spermatozoa } \\
\text { within subjects }\end{array}$} \\
\hline & Head & Mid-piece & Head & Mid-piece & Head & Mid-piece \\
\hline $\begin{array}{l}\mathrm{Na} \\
\mathrm{P} \\
\mathrm{S} \\
\mathrm{Cl} \\
\mathrm{K} \\
\mathrm{Ca} \\
\mathrm{Zn}\end{array}$ & $\begin{array}{r}5.06 \\
10.36 \\
1.52 \\
0.98 \\
3.12 \\
1.04 \\
0.34\end{array}$ & $\begin{array}{l}3.92 \\
4.74 \\
1.08 \\
1.21 \\
1.48 \\
4.14 \\
0.94\end{array}$ & $\begin{array}{l}1.96 \\
2.86 \\
0.28 \\
0.74 \\
0.77 \\
0.22 \\
0.10\end{array}$ & $\begin{array}{l}0.89 \\
1.08 \\
0.19 \\
0.61 \\
0.53 \\
1.99 \\
0.84\end{array}$ & $\begin{array}{l}1.59 \\
3.12 \\
0.38 \\
0.74 \\
0.97 \\
0.37 \\
0.11\end{array}$ & $\begin{array}{l}1.73 \\
1.60 \\
0.38 \\
1.01 \\
1.10 \\
3.01 \\
0.19\end{array}$ \\
\hline
\end{tabular}

Figures represent relative elemental weight concentrations (characteristic $\mathrm{X}$-ray emission/white radiation).

* Fifteen cells were analysed for each semen sample. The mean elemental concentration for each sample was calculated and the average of the means is presented.

$\dagger$ The variability between means of the six subjects is presented as the S.D.

$\ddagger$ The variability between individual cells for each sample is presented as the root mean square of the standard deviations for each sample.

Table 2. Ratio of relative concentrations of elements in normal human sperm cells

\begin{tabular}{lccc}
\hline \multicolumn{1}{c}{ Ratio } & $\begin{array}{c}\text { Average of mean } \\
\text { ratios from six } \\
\text { subjects }\end{array}$ & $\begin{array}{c}\text { Variability } \\
\text { between subjects } \\
\text { (S.D. of mean ratios) }\end{array}$ & $\begin{array}{c}\text { Variability } \\
\text { between spermatazoa } \\
\text { within subject } \\
\text { (S.D. of ratios })\end{array}$ \\
\hline $\mathrm{Na}: \mathrm{K}$ (head) & 1.71 & 0.51 & 0.46 \\
$\mathrm{Na}: \mathrm{K}$ (mid-piece) & 2.71 & 1.01 & 1.76 \\
$\mathrm{Ca}: \mathbf{P}$ (mid-piece) & 0.81 & 0.34 & 0.31 \\
\hline
\end{tabular}

Text-figure 3 shows that the copper had virtually no effect on the sodium:potassium ratio, particularly in the head region, but that there was a significant increase in the calcium: phosphorus ratio in the mid-piece $(P<0.001)$.

The incubation caused complete immotility of the spermatozoa.

\section{Cervical mucus incubations}

When spermatozoa were incubated with cervical mucus, there was no effect on motility, neither was there any change in the elemental content of the spermatozoa (Text-fig. 4 shows an analysis of ten cells) with the exception that 


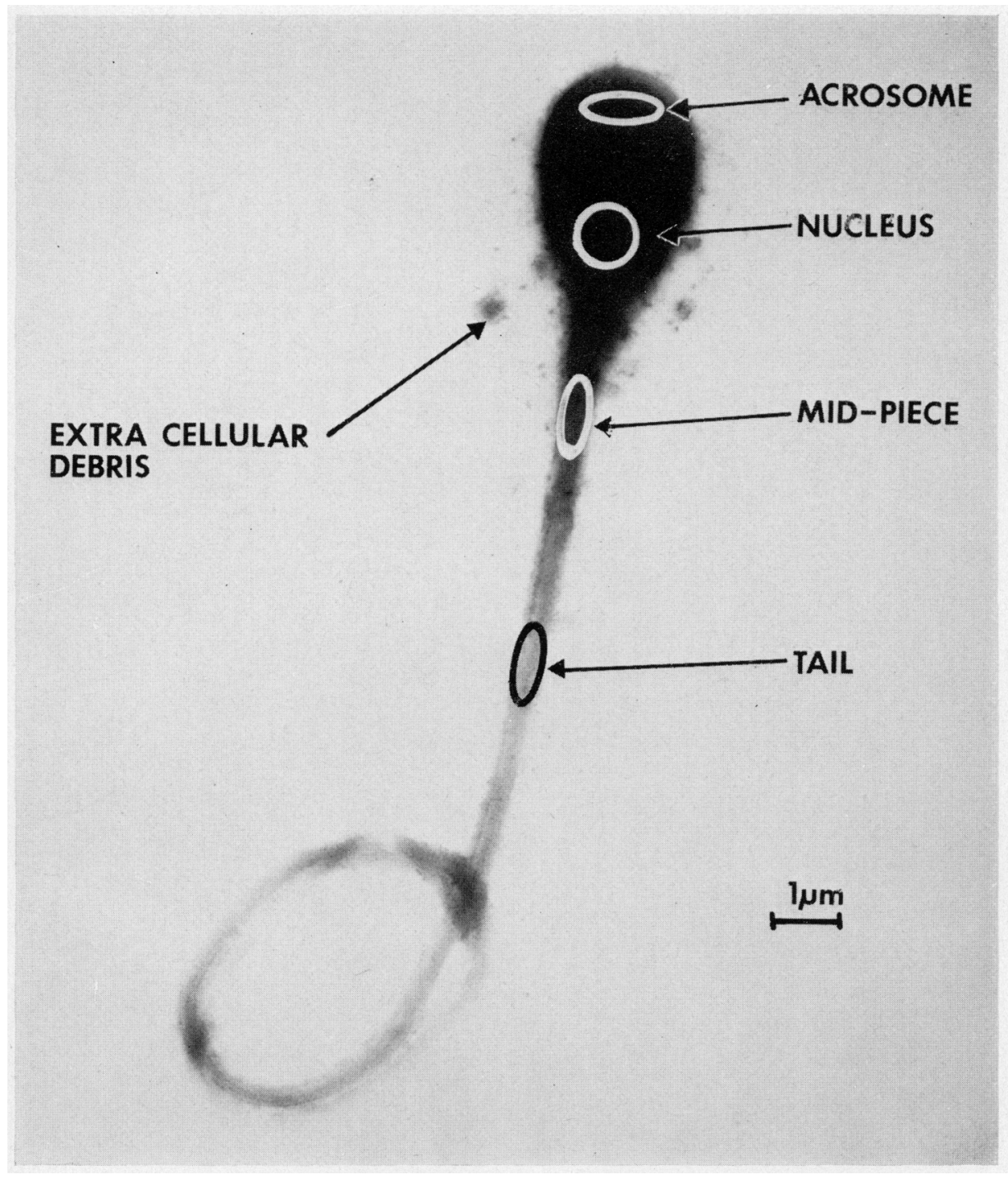

Human sperm cell analysed in the electron microscope, EMMA. The circles indicate areas of analysis chosen by focusing the electron probe on the specimen. 
the sodium to potassium ratio was significantly increased $(P<0.005)$ as shown in Text-fig. 5. When, however, the cervical mucus was pretreated with copper wire, or contained copper wire during the incubation with the spermatozoa, no motile spermatozoa were found in either sample. There was no further change

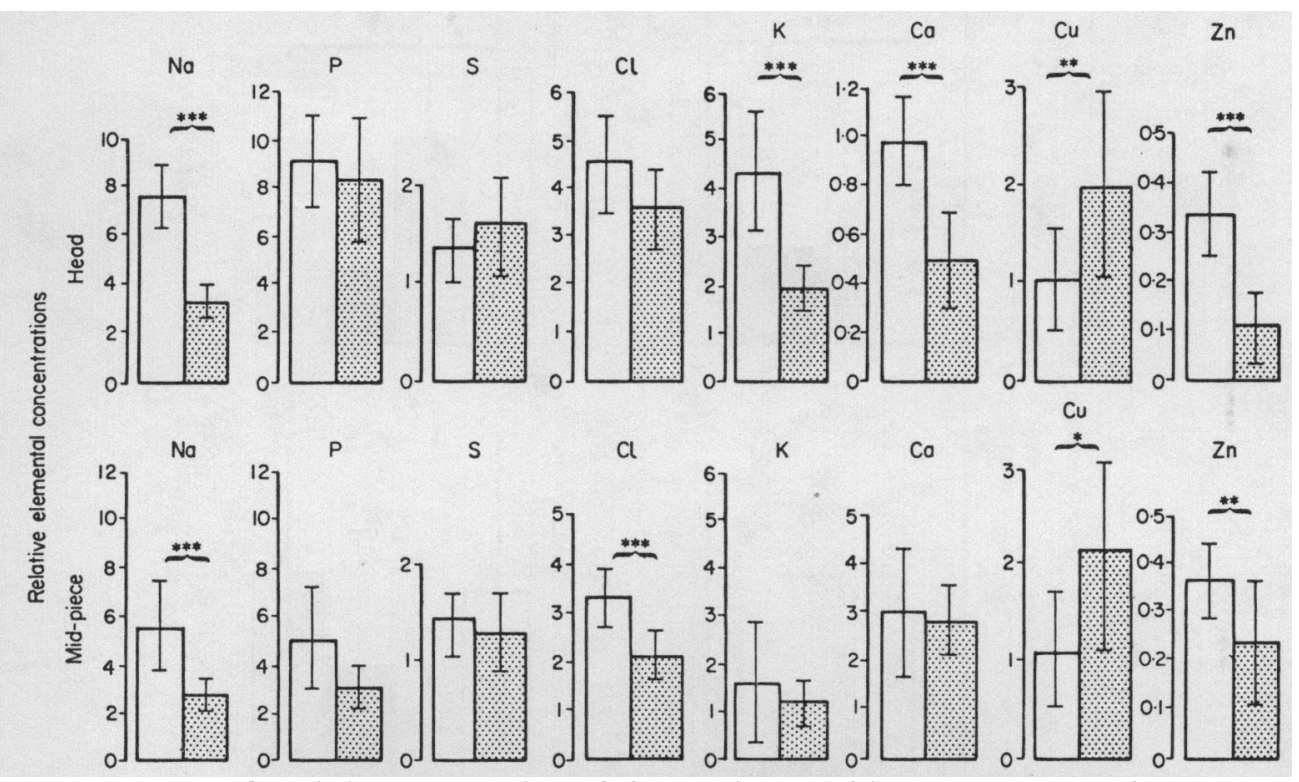

TExT-Fig. 2. Relative concentrations of elements in normal human spermatozoa incubated in semen with (stippled columns) and without (open columns) copper. Vertical bars represent one S.D. of the mean. *, $P<0.02 ;^{* *}, P<0.025 ;^{* *}, P<0.001$.

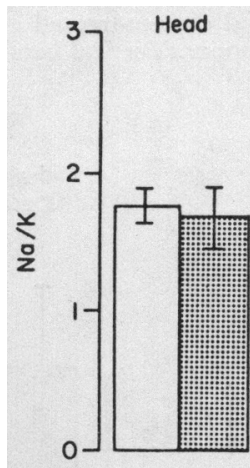

Mid-piece

Mid-piece

TexT-FIG. 3. Ratios of the relative concentrations of elements in normal human spermatozoa in semen incubated with (stippled columns) and without (open columns) copper. Vertical bars represent one S.D. of the mean. $* * *, P<0.001$.

in the sodium to potassium ratio. Incubating spermatozoa with the pretreated cervical mucus caused a significant $(P<0.001)$ decrease in the zinc content of the head region. Other elements remained unaffected. Where the copper wire was retained within the cervical mucus, the copper levels increased $(P<0.005)$ in the head and mid-piece regions. The calcium:phosphorus ratio appeared unaffected by the treatments. 


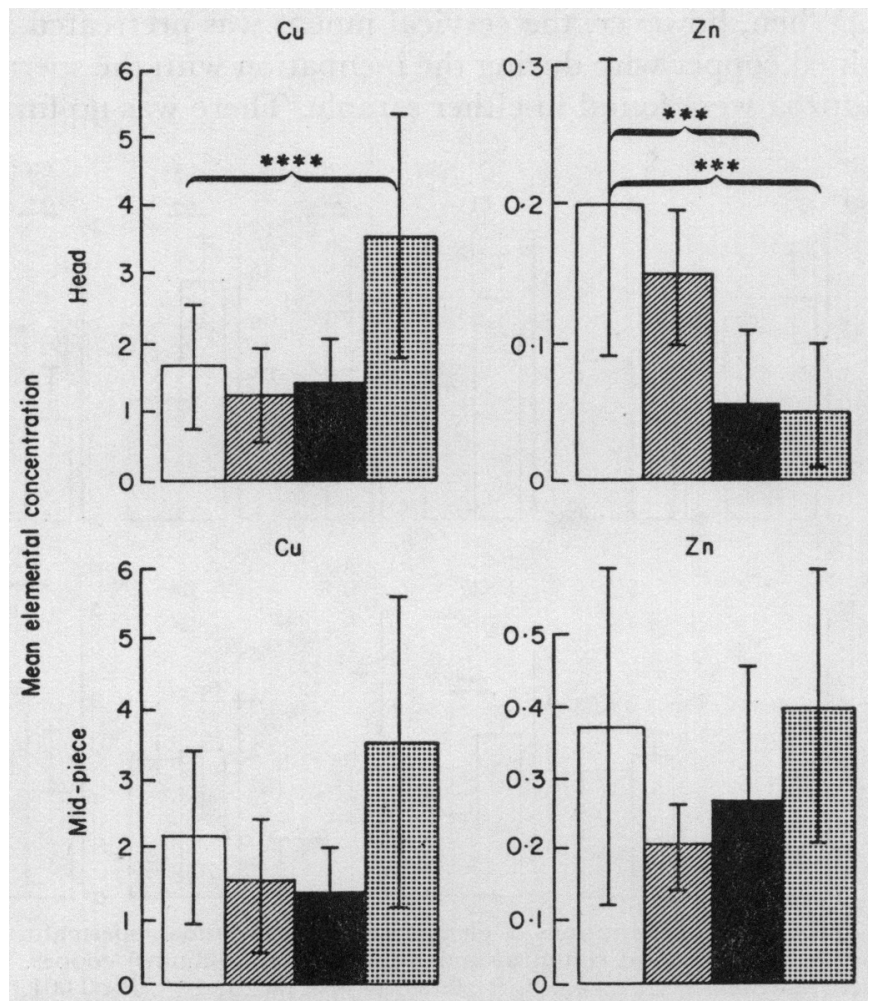

TEXT-FIG. 4. Relative concentrations of elements in spermatozoa (ten cells) incubated in semen (open columns), cervical mucus (hatched columns), and copper-treated cervical mucus with (stippled columns) and without (solid columns) copper. Vertical bars represent one S.D. ***, $P<0.001 ; * * * *, P<0.005$.

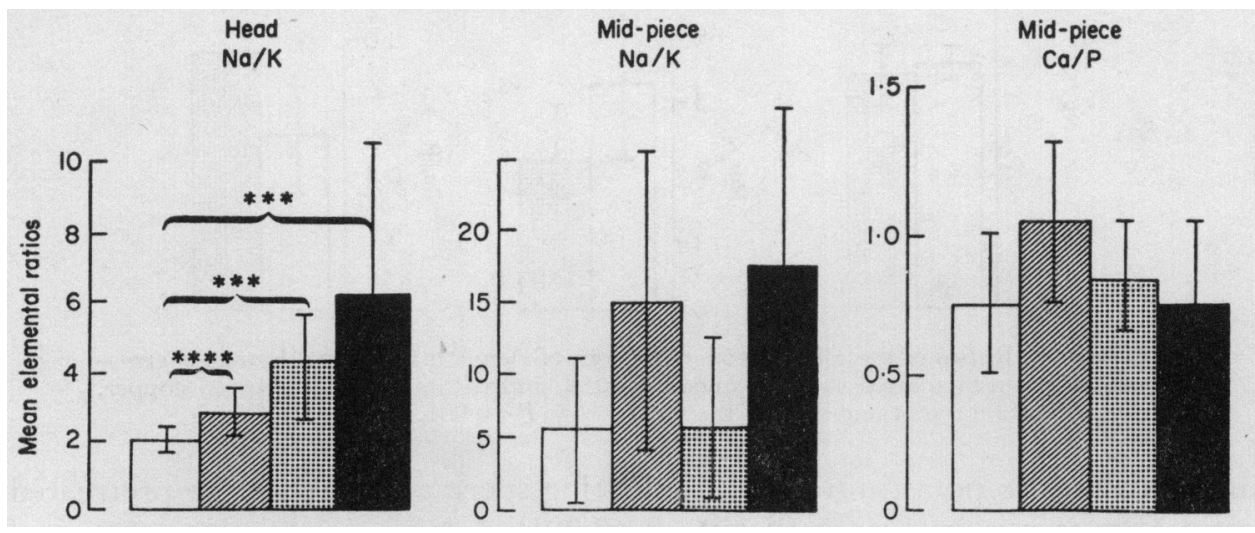

TEXT-FIG. 5. Ratio of relative concentrations of elements in normal human spermatozoa incubated in cervical mucus (hatched columns) in cervical mucus pretreated with copper (stippled columns), in cervical mucus containing copper and pre-treated with copper (solid columns) and in semen alone (open columns). Vertical bars represent one S.D. ***, $P<0.001$; **** $P<0.005$. 


\section{DISCUSSION}

In the studies on normal semen, the analysis of a small number of semen samples (see Table 1) showed that from one spermatozoon to another and from sample to sample, there was a constancy in the proportion of elements with the exception of chlorine.

In the metal incubation experiments, the ratio of sodium to potassium was notably constant. This may be of value in maintaining the membrane potentials required, for example, in motility. The evidence that sodium, potassium and chlorine can move more freely in and out of spermatozoa (McGrady \& Nelson, 1973), and our findings of a change in the sodium: potassium ratio after washing, may reflect adaptation to an environment with a different sodium and potassium content.

Earlier work by Keitel \& Jones (1956) had shown that in bulk samples there was a constant ratio of sodium to potassium of $3: 1$ in human spermatozoa and semen. In connection with the involvement of sodium and potassium in sperm motility, it has been suggested by Steinbach \& Dunham (1962) that the high potassium environment in the mammalian tract accounts for the relative immotility of spermatozoa before ejaculation and that a lowering of the external levels of potassium may cause contractility and tail movement. It is possible that there is an optimal content of potassium, above or below which the spermatozoa become less motile, although Bondani \& co-authors (1973) concluded that the levels of $\mathrm{Na}^{+}, \mathrm{K}^{+}, \mathrm{Cl}^{-}$and $\mathrm{Mg}^{++}$in semen have no correlation with sperm motility.

This variation may be contrasted with the effect of copper wire in semen which, whilst not affecting the sodium:potassium ratio (Text-fig. 3), yet caused a decrease in motility. In the incubations with mucus, the addition of copper again failed to affect the sodium:potassium ratio (Text-fig. 5). The importance of the concentrations of these electrolytes in relation to sperm motility therefore remains undecided.

Other elements have also been implicated in sperm motility. For example, Morisawa \& Mohri (1972) found that in sea-urchin spermatozoa there was more zinc present than could be accounted for in known zinc-containing enzymes and concluded that this element may be directly involved in motility. Although extrapolation to the mammalian situation is not always possible, it is of interest that in the present study the spermatozoa incubated with copper showed markedly reduced motility and had a significantly decreased zinc content (Text-fig. 4), particularly in the head but also in the mid-piece, together with an increase in copper content. This may reflect a decrease in the activity of metalloenzymes such as carbonic anhydrase and alkaline phosphatase which are thought to be involved in sperm motility.

Although the relationship between zinc and sperm motility still remains uncertain, this effect of copper wire may account for some of the efficiency of the Cu-releasing device. It is also possible that in addition to the effects on motility, there may also be some effect on fertility, perhaps by reduction of zinc levels in the acrosomal region, particularly as the zinc in the spermatozoa has been suggested as being involved in the spindle dynamics of the fertilized ovum of sea-urchins (Fujii, 1954). The zinc may also contribute to the 'fixed 
charge' described by Lindemann \& Rikmenspoel (1971) as creating a membrane potential and, by changing this, the motility of the spermatozoa could be decreased.

These changes in elemental content produced by copper may be associated with some decrease in the fertilizing potential of spermatozoa in women wearing Cu-releasing devices (Elstein \& Ferrer, 1973). More precise data are needed, however, on the critical lowest levels of copper which are required to exert a significant spermatotoxic effect and which may be reached in the cervical mucus, either from a copper-releasing IUD by increasing the surface area of its copper wire, or from a copper-releasing intracervical device which would rely principally on the prevention of sperm survival in the upper genital tract as its mode of action.

\section{ACKNOWLEDGMENTS}

The authors are grateful to the Tenovus Organization for generous financial support and to the World Health Organization (Geneva) for a personal grant to one of us (P.V.M.). We wish to express gratitude to Professor Keith Griffiths for his encouragement and advice. We would like to thank Mrs Frances Rush for technical assistance.

\section{REFERENCES}

Bondani, A., Aspeita, E., Anzar, R., Gomez-Arzapalo, E., Pascual, C. \& Giner, J. (1973) Correla tion between sperm motility and electrolyte composition of seminal fluid in normal and infertile men. Fert. Steril. 24, 150-154.

Brinster, R. L. \& CRoss, P. C. (1972) Effect of copper on preimplantation mouse embryo. Nature, Lond. 238, 398-399.

Chandrer, J. A. (1973) Recent developments in analytical electron microscopy. J. Microsc., Oxford, 98, 359-378.

Chandeer, J. A. (1974) X-ray microanalysis in cytochemistry. In Techniques of Biochemical and Biophysical Morphology, vol. 2, pp. 307-433. Ed. D. Glick. Wiley-Interscience, New York.

Chang, C. C., Tatum, H. J. \& Kincl, F. A. (1970) The effect of intrauterine copper and other metals on implantation in rats and hamsters. Fert. Steril. 21, 274-278.

Elstein, M. \& FerRer, K. (1973) The effect of a copper-releasing intrauterine device on sperm penetration in human cervical mucus in vitro. 7. Reprod. Fert. 32, 109-111.

FujII, T. (1954) Notes on the presence of zinc in nucleoli and in sperm middle-piece in some marine forms. Annotnes zool. jap. 27, 115-117.

Hall, T. A. (1971) The microprobe assay of chemical elements. In Physical Techniques in Biochemical Research, 2nd edn, pp. 158-275. Academic Press, London.

Keitel, H. G. \& Jones, H. S. (1956) The mineral and water composition of normal human sperm. 7. Lab. clin. Med. 47, 917-919.

Lindemann, C. \& Rikmenspoel, R. (1971) Intracellular potentials in bull spermatozoa. 7. Physiol., Lond. 219, 127-138.

McGrady, A. V. \& Neison, L. (1973) Electrophysiology of bull spermatozoa. Expl Cell Res. 76, 349-352.

Morisawa, M. \& Mohrr, H. (1972) Heavy metals and sperm motility. Expl Cell Res. 70, 311-316.

Oster, G. K. (1972) Chemical reactions of the copper intrauterine device. Fert. Steril. 23, 18-23.

Rush, F. \& ElsteIn, M. (1974) The effect of incubating a copper releasing intrauterine device on sperm penetration and the physical properties of cervical mucus. 7 . Obst. Gynaec. Br. Commonw. 81, $483-485$.

Saito, S., Bush, I. M. \& Whitmore, W. F. (1967) Effects of certain metals and chelating agents on rat and dog epididymal spermatozoan motility. Fert. Steril. 18, 517-529.

Steinbach, H. B. \& Dunham, P. B. (1962) Ionic balance of sperm cells. In Spermatozoan Motility, pp. 55-57. Ed. D. W. Bishop. Publication No. 72. Am. Ass. Advancement of Science, Washington D.C.

Zipper, J., Tatum, H. J., Medel, M., Pastene, L. \& Rivera, M. (1971) Contraception through the use of intrauterine metals. I. Copper as an adjunct to the 'T' device. Am. 7. Obstet. Gynec. 109, $771-774$.

Zipper, J. A., Tatum, H. J., Pastene, L., Medel, M. \& Rivera, M. (1969) Metallic copper as an intrauterine contraceptive adjunct to the 'T' device. Am. F. Obstet. Gynec. 105, 1274-1278. 